\title{
The axial transsacral approach to interbody fusion at L5-S1
}

\author{
Paul S. Issack, M.D., Ph.D., Suhel Y. Kotwal, M.D., and Oheneba Boachie-Adjei, M.D. \\ Hospital for Special Surgery, New York, New York
}

\begin{abstract}
Lumbosacral interbody fusion may be indicated to treat degenerative disc disease at L5-S1, instability or spondylolisthesis at that level, and severe neural foraminal stenosis resulting from loss of disc space height. In addition, L5-S1 interbody fusion may provide anterior support to a long posterior fusion construct and help offset the stresses experienced by the distal-most screws. There are 3 well-established techniques for L5-S1 interbody fusion: anterior lumbar interbody fusion, posterior lumbar interbody fusion, and transforaminal lumbar interbody fusion. Each of these has advantages and pitfalls. A more recently described axial transsacral technique, utilizing the presacral corridor, may represent a minimally invasive approach to obtaining lumbosacral interbody arthrodesis. Biomechanical studies demonstrate that the stiffness of the axial rod is comparable to existing fixation devices, suggesting that, biomechanically, it may be a good implant for obtaining lumbosacral interbody fusion. Clinical studies have demonstrated good early results with the use of the axial transsacral approach in obtaining lumbosacral interbody fusion for degenerative disc disease, spondylolisthesis, and below long posterior fusion constructs. The technique is exacting and complications can be major, including rectal perforation and fistula, loss of correction, and pseudarthrosis. (http://thejns.org/doi/abs/10.3171/2014.2.FOCUS13467)
\end{abstract}

$\begin{array}{llcllll}\text { KEY WoRds } & \bullet & \text { lumbosacral interbody fusion } & \bullet & \text { presacral } & \bullet & \text { transsacral } \\ \text { degenerative } & \bullet & \text { AxiaLIF } & \bullet \quad \text { adult scoliosis }\end{array}$

I NTERBODY fusion at L5-S1 is indicated for specific pathology including degenerative disc disease, ${ }^{12}$ instability, ${ }^{33}$ neural foraminal stenosis, ${ }^{5,32}$ and protection of S-1 screws at the end of long fusion constructs to the sacrum..$^{3,8,34}$ Interbody fusion at L5-S1 may be achieved anteriorly (anterior lumbar interbody fusion [ALIF]), posteriorly (posterior lumbar interbody fusion [PLIF]), or via the neural foramen (transforaminal lumbar interbody fusion [TLIF]). These techniques have specific advantages and pitfalls, making none of them the ideal approach for lumbosacral fusion. The more recently described transsacral axial lumbar interbody fusion (AxiaLIF) addresses some of the concerns of the previous fusion techniques. Early evidence suggests that the technique may be performed safely to achieve L5-S1 fusion for degenerative disc disease, spondylolisthesis, and at the distal end of long posterior fusion constructs. This review will focus on the biomechanical studies, early clinical outcomes, and complications of the axial transsacral approach to lumbosacral interbody fusion.

Abbreviations used in this paper: ALIF = anterior lumbar interbody fusion; AxiaLIF = axial lumbar interbody fusion; PLIF = posterior lumbar interbody fusion; TLIF = transforaminal lumbar interbody fusion.

\section{Current Approaches to L5-S1 Interbody Arthrodesis}

There are 3 well-established methods to obtain L5S1 interbody arthrodesis. An ALIF requires a retroperitoneal approach to reach the L5-S1 interspace below the bifurcation of the aorta into the left and right common iliac arteries. ${ }^{10}$ This direct access allows for release of the anterior longitudinal ligament and restoration of sagittal alignment using a lordotic graft with a large footprint. The anterior approach can help restore sagittal balance, increase neural foraminal height, and lead to high fusion rates. ${ }^{5,14,32}$ However, the exposure risks injury to the iliac vessels (especially the thin-walled common iliac vein that is adjacent to the L5-S1 disc space on the left side) and the sympathetic plexus, which can cause retrograde ejaculation in males. ${ }^{10,26}$ The PLIF and TLIF cages are smaller than ALIF cages, necessitated by the limited space for entry around the cauda equina and nerve roots; the smaller size results in a smaller footprint and a potentially lower rate of arthrodesis. ${ }^{7}$ Retraction to place these cages can result in neurological injury.,25,28 In the majority of cases, the direct lateral interbody approach (DLIF or XLIF [extreme-lateral interbody fusion]) cannot be used to obtain interbody arthrodesis at L5-S1 because of the overhang 


\section{P. S. Issack, S. Y. Kotwal, and O. Boachie-Adjei}

of the iliac wing and obstruction by the nerve roots of the lumbosacral plexus. ${ }^{27}$

\section{The Axial Transsacral Approach to L5-S1 Interbody Arthrodesis}

The axial transsacral approach to interbody fusion at L5-S1 allows for placement of a cylindrical cage (AxiaLIF, TranS1) through the presacral corridor. The AxiaLIF implant has a reverse thread pitch to provide interspace distraction during implantation (Fig. 1). This technique has certain potential advantages including a musclesparing approach and complete preservation of the anulus fibrosus. ${ }^{22,28}$ The minimally vascular presacral corridor allows for safe implant placement with little risk for vascular injury. ${ }^{22}$ However, the trajectory must be very precise as the implant is navigated posterior to the rectum, and rectal injury has been reported in conjunction with this technique. ${ }^{4,19}$ Biomechanical and preliminary clinical data suggest good short-term outcomes for axial lumbar interbody fusion for degenerative disc disease, spondylolisthesis and as anterior support caudal to long fusion constructs..$^{6,9,17,20}$

\section{Biomechanical Evaluation}

Biomechanical studies have shown that the axial transsacral introduction of a fusion cage is technically feasible and that the fixation properties of this technique are comparable to those of existing implants for lumbosacral arthrodesis..$^{6,9,17,20}$ Ledet and colleagues ${ }^{17}$ mechanically tested 24 bovine lumbar motion segments in sagittal and lateral bending, torsion, and axial compression after drilling an axial canal and implanting a fixation rod within the drilled canal. Drilling had little effect on stiffness and range of motion of the specimens. However, specimens implanted with the axial rod demonstrated significant decreases in range of motion and increases in stiffness relative to the intact state. Compared with results reported for existing anterior, posterior, and interbody instrumentation, specifically femoral ring allograft, BAK cages, Brantigan ALIF and TLIF implants, Harms cages, and Kaneda, Isola, and University plating systems, lateral and sagittal bending stiffness of the axial rod was greater, whereas stiffness in extension and axial compression was similar to plate and rod constructs. Torsional stiffness was similar to that of interbody constructs and lower than that of plate and rod constructs. Thus the stiffness of the axial rod is comparable to or greater than that of existing fixation devices, which suggests that biomechanically it is a good implant for obtaining lumbosacral interbody fusion. ${ }^{17}$

Erkan and colleagues ${ }^{9}$ have tested 2-level fusion (L4S1) using the axial rod technique. Six human cadaveric L4-S1 motion segments were tested in axial torsion, lateral bending, and flexion-extension following intact, standalone AxiaLIF (2-level rod), and AxiaLIF with posterior fixation and either facet screw or pedicle screw placement. At the L4-5 level in axial torsion and flexion-extension, none of the surgical treatments showed any statistical significance. In lateral bending, the posterior fixation devices had significantly higher construct stability compared with

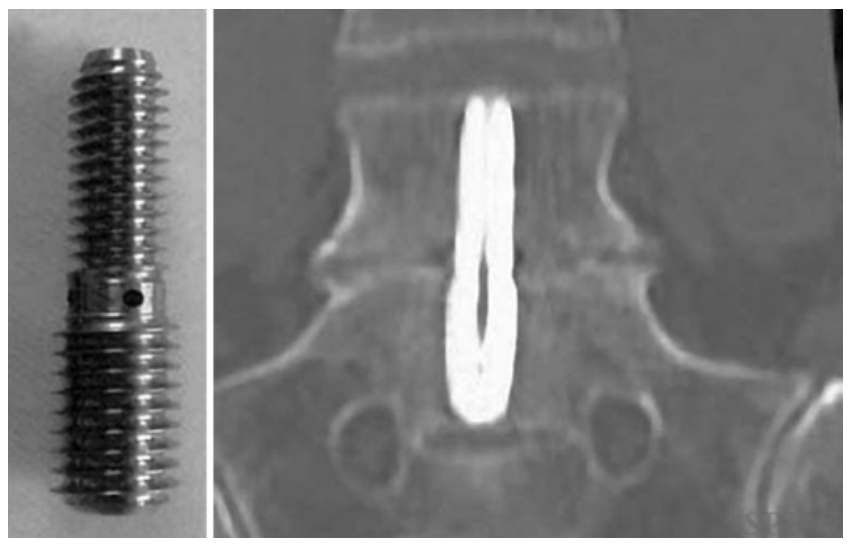

FIG. 1. Left: The AxiaLIF implant with reverse thread pitch to provide interspace distraction during implantation. Right: An AxiaLIF rod implanted in the L5-S1 disc space. Adapted with permission from Lippincott Williams and Wilkins/Wolters Kluwer Health: Tobler WD et al.: Minimally invasive axial presacral L5-S1 interbody fusion: two-year clinical and radiographic outcomes. Spine 36(20):E1296-E1301, 2011.

the stand-alone AxiaLIF. At the L5-S1 level in axial torsion and lateral bending, none of the surgical treatments showed statistically significant differences. However, in flexion-extension, the stand-alone AxiaLIF had significantly greater range of motion than the posterior fixation techniques, suggesting that AxiaLIF should be performed in conjunction with posterior fixation to achieve greater stability for a successful arthrodesis. ${ }^{9}$

\section{Surgical Procedure}

The patient undergoes a standard bowel preparation 24 hours prior to surgery. The procedure is performed with the patient prone and a pillow placed beneath the pelvis for elevation. Preoperative antibiotic agents are administered. The sacrococcygeal region is prepared and draped in the standard sterile fashion. If a prior posterior spinal fusion had been performed at the same operative setting, the posterior wound is closed and the patient is re-prepped and draped for the axial interbody procedure. This re-prepping minimizes infection risk and allows for optimal patient positioning in lumbosacral lordosis to help with implant targeting into the vertebral body of L-5. A $3-\mathrm{cm}$ transverse incision is made at the right side of the coccyx and carried through the subcutaneous tissue to the fascia. The anterior surface of the coccyx is located with a curved Kelly clamp. Using biplanar fluoroscopy, a blunt dissecting tool (TranS1) is then advanced along the anterior face of the sacrum to the S1-2 level where it is docked (Fig. 2A). The inner blunt stylet is exchanged for a guide pin, which is introduced into the S-1 vertebral body, across the L5-S1 disc space under fluoroscopic visualization (Fig. 2B). A series of dilators opens the osseous path, allowing for placement of a working cannula; through this cannula, a path is drilled from the anterior sacrum through S-1 into the L5-S1 disc space. Radial cutting instruments are used to perform the discectomy and prepare the endplates for fusion (Fig. 2C). Cutting instruments should not be turned $360^{\circ}$ as they may invade 


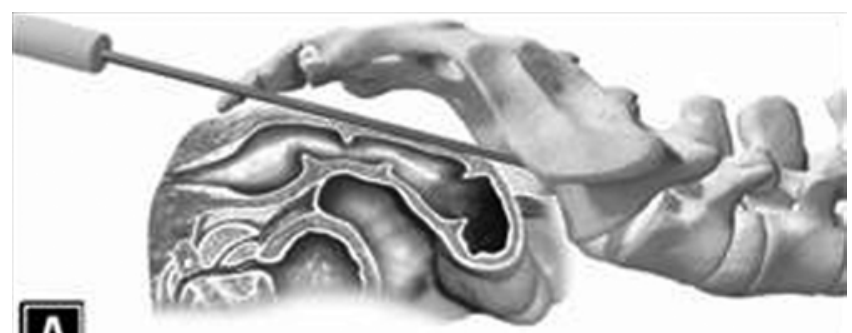

A
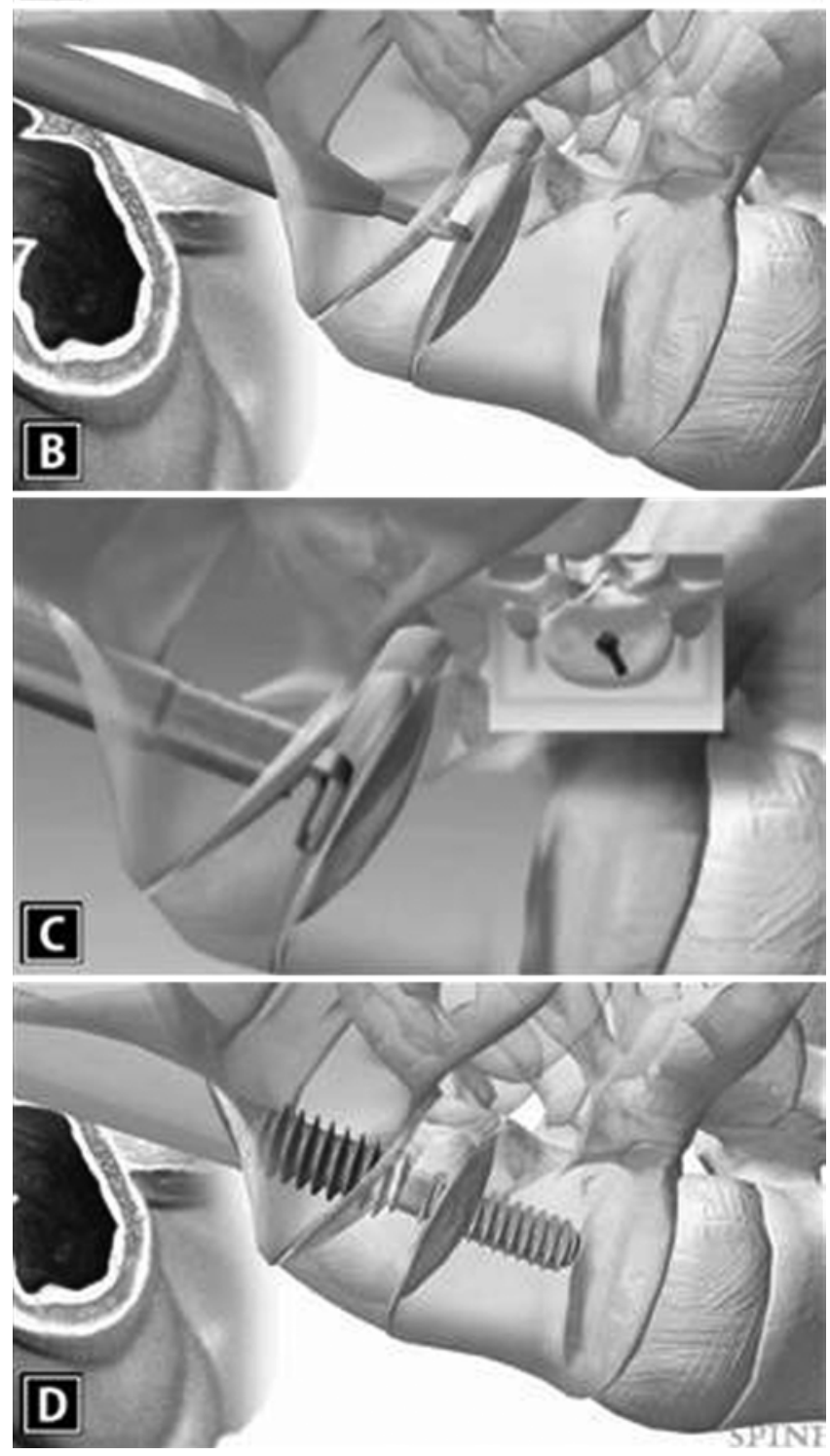

FIG. 2. AxiaLIF surgical technique. A: The guide pin is introduced into the presacral space over a blunt stylet and is docked on the anterior face of the sacrum. B: The dilator and guide pin are introduced into the L5-S1 disc space. C: Radial cutters are used to perform discectomy and prepare endplates for fusion. D: Implantation of AxiaLIF rod and bone grafting are performed. Reproduced with permission from: Tobler WD et al.: Minimally invasive axial presacral L5-S1 interbody fusion: two-year clinical and radiographic outcomes. Spine 36(20):E1296E1301, 2011. the spinal canal. After discectomy, the disc space is filled with bone graft material composed of local bone removed from the vertebral body and demineralized bone matrix. The appropriate length AxiaLIF implant is inserted over a guide pin through a protective cannula, transfixing the L5-S1 level (Fig. 2D). The wound is irrigated and closed after removal of guide wires and cannulas.

$\mathrm{Li}$ and colleagues, ${ }^{18}$ in a human cadaveric study, dissected the presacral space in 16 pelvic specimens and observed the position of the entry guide pin for AxiaLIF in relation to the pelvic splanchnic nerves. The pelvic splanchnic nerves limited the dissection of the lower rectum, and the minimum distance from the guide pin to the pelvic splanchnic nerves was as small as $4 \mathrm{~mm}$. Clearly the margin of error is small, and the accurate placement of the blunt stylet through which the guide pin is passed is the most critical step in the operation.

\section{Treating Degenerative Disc Disease and Spondylolisthesis With AxiaLIF}

The majority of clinical studies on the axial interbody technique involve treatment of degenerative disc disease and spondylolisthesis. $3,11,12,22,30,31$ Aryan and colleagues ${ }^{3}$ reviewed data obtained in 35 patients with back pain due to lumbar degenerative disc disease, degenerative scoliosis, or isthmic spondylolisthesis treated with AxiaLIF and recombinant human bone morphogenetic protein. Twentythree patients underwent supplemental posterior pedicle screw fixation. In 32 patients (91\%), there was clinical and radiographic evidence of L5-S1 interbody fusion at a mean follow-up of 17.5 months. Tobler and Ferrara ${ }^{30}$ prospectively followed up 26 patients with degenerative disc disease who underwent AxiaLIF with posterior pedicle screw fixation for 2 years. The fusion was at 1 level (L5S1) in 17 patients and at 2 levels (L4-S1) in 9 patients. Interbody fusion was achieved at 1 year in 22 patients and 2 years in 23 patients. One patient with a pseudarthrosis underwent successful revision posterolateral fusion. In a larger retrospective study, Tobler and colleagues ${ }^{31}$ evaluated 156 patients who underwent an L5-S1 interbody fusion in which an AxiaLIF rod was used (Fig. 3). There were significant improvements in pain and mean Oswestry Disability Index scores at the 2-year follow-up. Radiographic evidence of interbody fusion was observed in $94 \%$ of the patients (145 of 155).

Gerszten and colleagues ${ }^{11}$ reported on 26 patients with Grade 1 or Grade 2 symptomatic L5-S1 isthmic spondylolisthesis who underwent L5-S1 AxiaLIF and posterior pedicle screw fixation. Approximately half the patients showed a reduction of at least one grade. Axial pain improved after AxiaLIF with a $66 \%$ reduction from baseline. The fusion rate at 2 years was $100 \%$ with outcome in $81 \%$ of patients deemed excellent or good according to Odom criteria. $^{11}$

\section{AxiaLIF Caudal to Long Fusion Constructs}

In adult deformity surgery, long posterior fusion constructs must often be extended to include L5-S1 in situations where there is lumbosacral disc degeneration, 

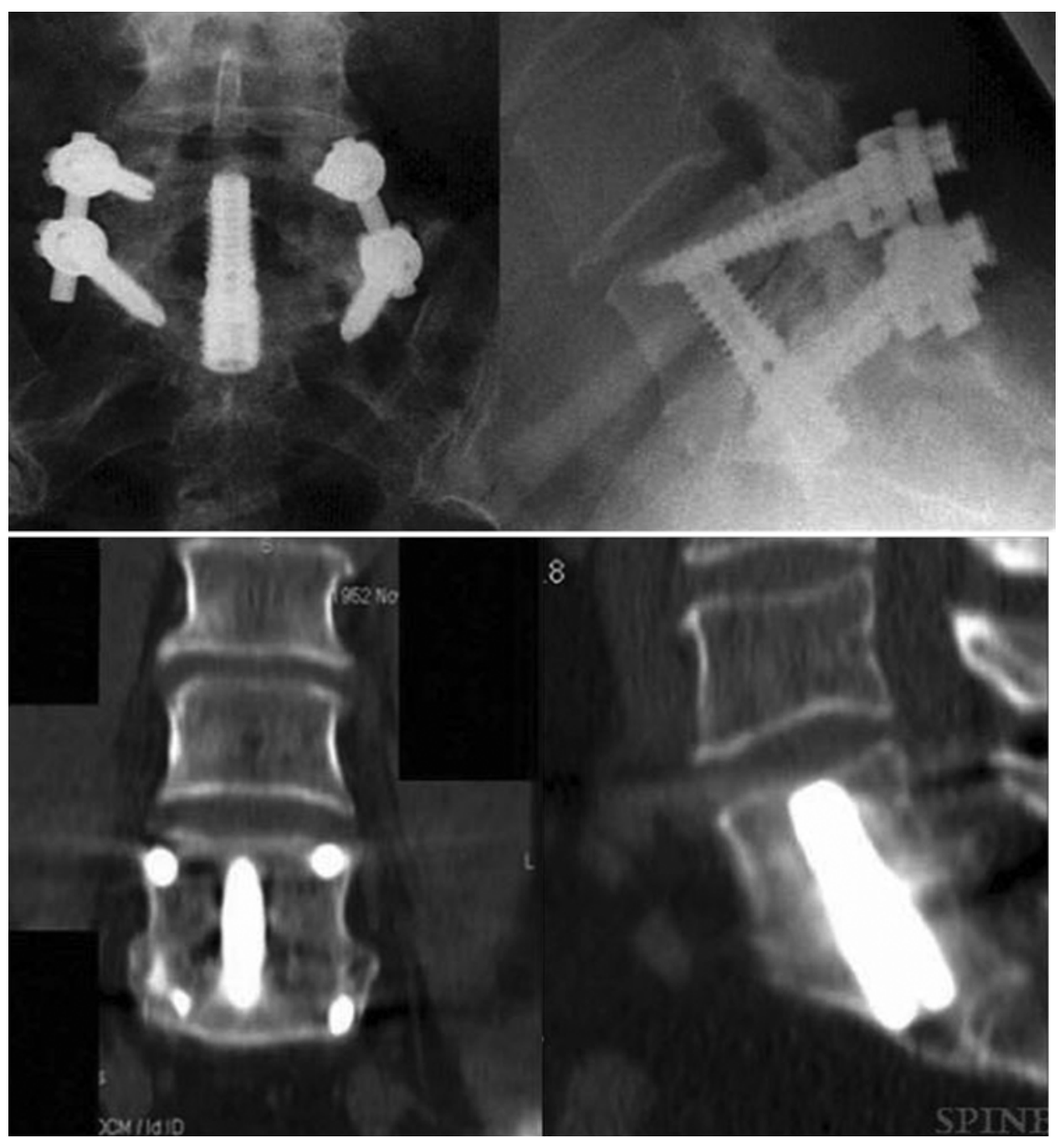

FIG. 3. Upper: Anteroposterior and lateral radiographs demonstrating L5-S1 interbody fusion with the AxiaLIF rod and pedicle screw fixation. Lower: Coronal and sagittal CT images demonstrating L5-S1 arthrodesis. Adapted with permission from Lippincott Williams and Wilkins/Wolters Kluwer Health: Tobler WD et al.: Minimally invasive axial presacral L5-S1 interbody fusion: two-year clinical and radiographic outcomes. Spine 36(20):E1296-E1301, 2011.

spondylosis, degenerative spondylolisthesis, or a fractional lumbosacral curve greater than $15^{\circ}$ in magnitude..$^{1,16,24}$ To protect distal fixation, particularly S-1 screws, the addition of iliac screws and anterior interbody support at L5-S1 is recommended to offset load on distal fixation. ${ }^{3,8,34}$ While interbody fusion at L5-S1 caudal to long fusion constructs has traditionally been achieved using an ALIF, PLIF, or TLIF, the axial interbody approach has recently been demonstrated to provide anterior support distal to long posterior fusions at short-term follow-up (Fig. 4).

Anand and colleagues ${ }^{1}$ evaluated circumferential fusion for lumbar degenerative scoliosis in 12 patients, of whom 5 had fusions to L5-S1 performed using the axial technique. There were no complications. Blood loss was less than $200 \mathrm{ml}$. Fusions extended as proximal as T-12 in these 5 AxiaLIF cases. ${ }^{1}$ In a retrospective study of 28 patients who underwent minimally invasive correction and fusion over 3 or more levels for adult scoliosis, Anand and associates $^{2}$ performed 13 one-level (L5-S1) and 4 two- level (L4-S1) axial interbody fusions. At a mean follow-up of 22 months, fusion had been achieved in all patients. There were no complications related to the AxiaLIF procedure. Blood loss was $231 \mathrm{ml}$ (including that associated with the placement of posterior instrumentation). These results suggest good outcomes using the axial transsacral technique to fuse L5-S1 below posterior fusion constructs extending up to T-12.,

Issack and Boachie-Adjei retrospectively examined 9 patients who underwent axial interbody fixation and fusion caudal to long fusion constructs for adult scoliosis. There were 4 one-level and 5 two-level procedures. Fusions in this series were longer than those described above, with 6 patients having fusions extending proximally to T-10 or higher (up to T-3). There were 2 pseudarthroses, and no major complications occurred. There were significant improvements in the pain, self-image and satisfaction with management domains of the SRS-22 (Scoliosis Research Society questionnaire).$^{15}$ 


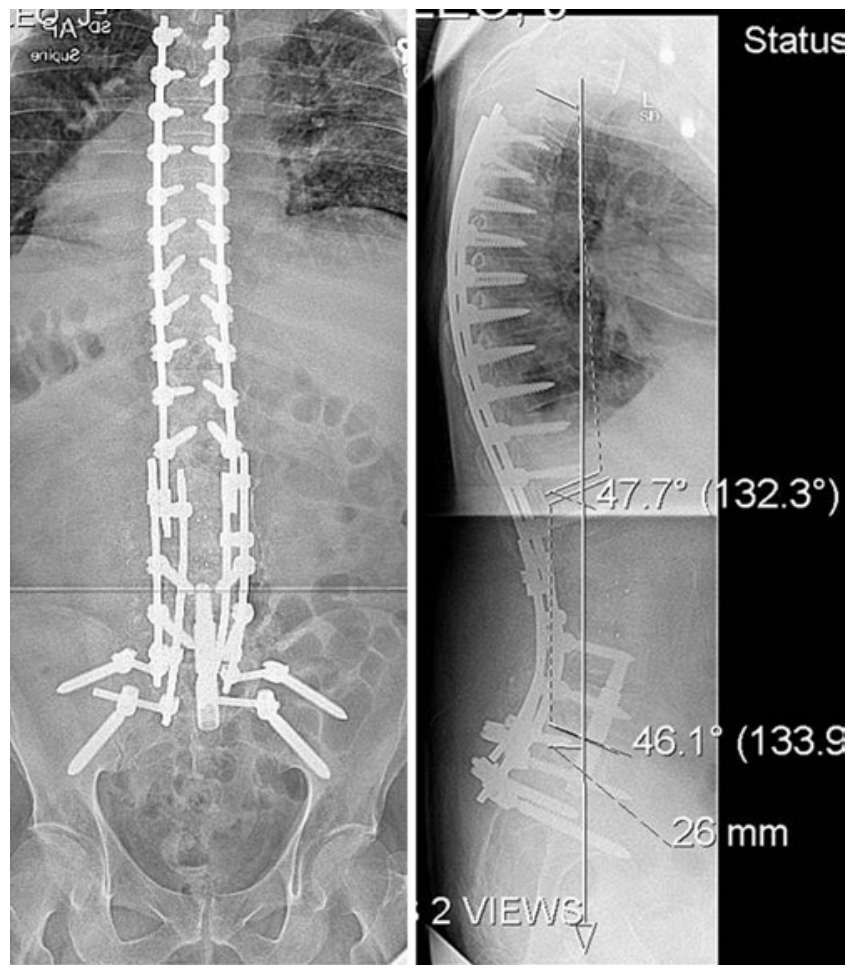

Fig. 4. Anteroposterior and lateral radiographs demonstrating a 2-level (L4-S1) AxiaLIF implanted caudal to a long posterior fusion construct.

\section{Complications}

A number of recently published case reports have described rectal perforation in association with the AxiaLIF surgery. ${ }^{4,19,23}$ Botolin and colleagues ${ }^{4}$ reported the case of a 44-year-old woman with a history of anterior and posterior spinal surgeries, pelvic inflammatory disease, and diverticulitis who underwent L5-S1 axial interbody fusion. After surgery, she presented with abdominal pain, nausea, vomiting, and melena. An abdominal CT scan after intravenous and oral contrast administration demonstrated soft-tissue fluid density with fat stranding in the presacral space. There was extraluminal rectal contrast and gas consistent with rectal perforation (Fig. 5). The patient required a diverting ileostomy with intravenous antibiotics. The authors suggested that a preoperative pelvic CT scan with rectal contrast be acquired in patients at risk for adhesion formation. Mazur and colleagues ${ }^{23}$ reported on a patient presenting with progressive back pain and sepsis 3 weeks after an L5-S1 AxiaLIF procedure. The patient required diverting colostomy and antibiotic treatment. She went on to develop a nonunion, which was treated with revision posterior spinal fusion and no explantation of the AxiaLIF device. Siegel and colleagues ${ }^{29}$ reported on the development of a rectocutaneous fistula in a 35-year-old man after L5-S1 AxiaLIF. The patient presented with sepsis and bloody drainage from the surgical site. A CT fistulagram and flexible sigmoidoscopy showed evidence of a rectocutaneous fistula, which was managed with intravenous antibiotics. At 6 months, the patient developed a pseudarthrosis that required surgical revision. ${ }^{29}$

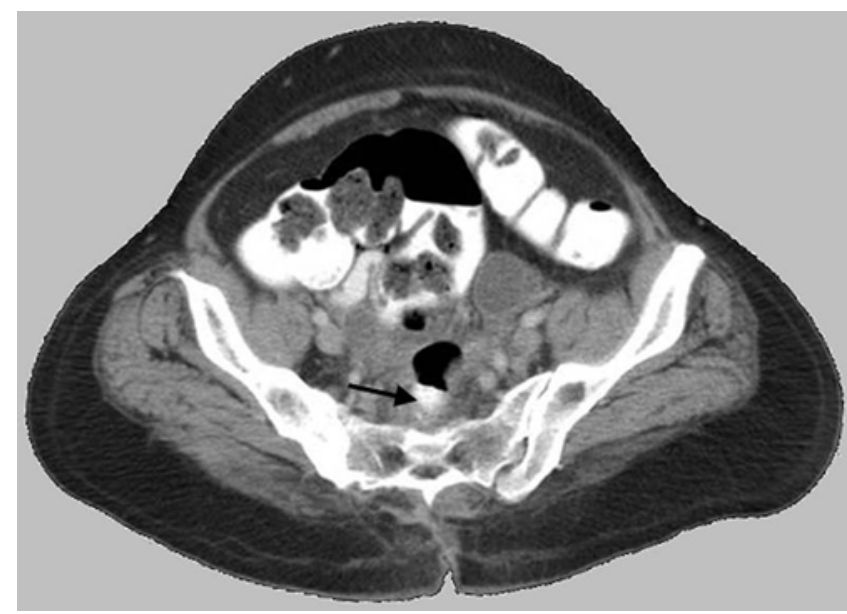

FIG. 5. Abdominal CT scan obtained after intravenous and oral contrast administration demonstrating soft-tissue fluid density with fat stranding in the presacral space. There is extraluminal rectal contrast and gas present consistent with high rectal perforation (arrow). Reproduced with permission from: Botolin et al.: High rectal injury during trans-1 axial lumbar interbody fusion L5-S1 fixation: a case report. Spine 35(4):E144-E148, 2010.

Pseudarthrosis is a concern when using the 2-level AxiaLIF procedure. Issack and Boachie-Adjei ${ }^{15}$ reported two pseudarthroses in their series: one at L4-5 and the other at L5-S1. One of these patients had a near $10-\mathrm{cm}$ positive sagittal balance after AxiaLIF. Although the numbers are too small in this series to draw statistically significant conclusions, restoration of sagittal balance is likely to be important for interbody fusion. Furthermore, thorough and meticulous discectomy and endplate preparation followed by robust bone grafting are likely essential components (as in ALIF, TLIF, and PLIF) of successful arthrodesis. Hofstetter and colleagues ${ }^{13}$ retrospectively reviewed data obtained in 38 patients who underwent either 1-level (32 patients) or 2-level (6 patients) AxiaLIF; the mean follow-up period was 26 months. Graft subsidence eliminated partial correction of segmental lordosis. At final follow-up, 72\% of L5-S1 levels exhibited bony fusion $(80 \%$ of the 1 -level and $33 \%$ of the 2 -level AxiaLIF procedures). None of the L4-5 levels in 2-level AxiaLIF fused. Five patients required revision fusion. The authors suggested that the axial rod provides inadequate longterm anterior column support. Marchi and colleagues ${ }^{21}$ prospectively followed up 27 patients who underwent the AxiaLIF procedure at L4-5 and L5-S1. In minimum follow-up period of 2 years, the authors observed multiple implant-related complications including screw breakage (15\%), proximal/distal transsacral rod detachment (11\%), and superior rod migration (24\%). At 2-year follow-up, the disc space was diminished in comparison with the preoperative status, segmental lordosis was diminished, and only $22 \%$ of all treated levels exhibited a solid fusion. ${ }^{21}$

Lindley and colleagues ${ }^{19}$ retrospectively reviewed complications in 68 patients who underwent AxiaLIF. Sixteen patients $(23.5 \%)$ suffered complications including rectal perforation (2 patients), pseudarthrosis (6 patients), superficial infection (4 patients), pelvic hematoma (2 patients), and sacral fracture ( 2 patients). With regard to 
superficial infection, we found that making a transverse incision, instead of a longitudinal incision, reduced this risk. To prevent pelvic hematoma, we recommend that all patients undergo preoperative MRI to document a clear fat plane separating the visceral peritoneum and rectum from the anterior sacral wall. If extensive vasculature is seen in this plane, AxiaLIF is contraindicated, as instruments cannot be safely passed through the presacral space. To prevent sacral fracture, the trajectory of the guide pin is critical. Too anterior a path may result in fracture of the anterior sacral cortex when either instruments or the implant is inserted. A trajectory that is too posterior may result in posterior vertebral cortical penetration with possible neural element injury.

\section{Conclusions}

The axial transsacral approach to L5-S1 provides a minimally invasive approach to interbody arthrodesis at L5-S1. Biomechanical studies on the AxiaLIF implant suggest stiffness comparable to existing interbody fixation devices. Early clinical studies on the AxiaLIF demonstrate good to excellent results in terms of pain relief and fusion rates when performing L5-S1 arthrodesis to treat degenerative disc disease and spondylolisthesis. Shortterm follow-up studies on the use of the axial interbody fusion caudal to long fusion constructs demonstrate good pain relief and fusion rates and minimal blood loss. The technique, however, is exacting and complications can be major. Emerging reports demonstrate a poor fusion rate with the 2-level construct. Long term follow-up studies to assess clinical outcome, fusion, and complications are required before the axial procedure can be recommended as a standard, routine approach to achieve L5-S1 interbody arthrodesis in adult scoliosis.

\section{Disclosure}

Dr. Boachie-Adjei reports being a consultant for Baxano, K2M, DePuy, and Medtronic.

Author contributions to the study and manuscript preparation include the following. Conception and design: all authors. Acquisition of data: all authors. Analysis and interpretation of data: all authors. Drafting the article: all authors. Critically revising the article: all authors. Reviewed submitted version of manuscript: all authors. Approved the final version of the manuscript on behalf of all authors: Issack. Statistical analysis: Kotwal, Boachie-Adjei. Administrative/technical/material support: all authors.

\section{References}

1. Anand N, Baron EM, Thaiyananthan G, Khalsa K, Goldstein TB: Minimally invasive multilevel percutaneous correction and fusion for adult lumbar degenerative scoliosis: a technique and feasibility study. J Spinal Disord Tech 21:459-467, 2008

2. Anand N, Rosemann R, Khalsa B, Baron EM: Mid-term to long-term clinical and functional outcomes of minimally invasive correction and fusion for adults with scoliosis. Neurosurg Focus 28(3):E6, 2010

3. Aryan HE, Newman CB, Gold JJ, Acosta FL Jr, Coover C, Ames CP: Percutaneous axial lumbar interbody fusion (AxiaLIF) of the L5-S1 segment: initial clinical and radiographic experience. Minim Invasive Neurosurg 51:225-230, 2008

4. Botolin S, Agudelo J, Dwyer A, Patel V, Burger E: High rec- tal injury during trans-1 axial lumbar interbody fusion L5-S1 fixation: a case report. Spine (Phila Pa 1976) 35:E144-E148, 2010

5. Chen D, Fay LA, Lok J, Yuan P, Edwards WT, Yuan HA: Increasing neuroforaminal volume by anterior interbody distraction in degenerative lumbar spine. Spine (Phila Pa 1976) 20:74-79, 1995

6. Cragg A, Carl A, Casteneda F, Dickman C, Guterman L, Oliveira C: New percutaneous access method for minimally invasive anterior lumbosacral surgery. J Spinal Disord Tech 17:21-28, 2004

7. DiPaola CP, Molinari RW: Posterior lumbar interbody fusion. J Am Acad Orthop Surg 16:130-139, 2008

8. Emami A, Deviren V, Berven S, Smith JA, Hu SS, Bradford DS: Outcome and complications of long fusions to the sacrum in adult spine deformity: Luque-Galveston, combined iliac and sacral screws, and sacral fixation. Spine (Phila Pa 1976) 27: 776-786, 2002

9. Erkan S, Wu C, Mehbod AA, Hsu B, Pahl DW, Transfeldt EE: Biomechanical evaluation of a new AxiaLIF technique for two-level lumbar fusion. Eur Spine J 18:807-814, 2009

10. Fantini GA, Pappou IP, Girardi FP, Sandhu HS, Cammisa FP Jr: Major vascular injury during anterior lumbar spinal surgery: incidence, risk factors, and management. Spine (Phila Pa 1976) 32:2751-2758, 2007

11. Gerszten PC, Tobler W, Raley TJ, Miller LE, Block JE, Nasca RJ: Axial presacral lumbar interbody fusion and percutaneous posterior fixation for stabilization of lumbosacral isthmic spondylolisthesis. J Spinal Disord Tech 25:E36-E40, 2012

12. Gerszten PC, Tobler WD, Nasca RJ: Retrospective analysis of L5-S1 axial lumbar interbody fusion (AxiaLIF): a comparison with and without the use of recombinant human bone morphogenetic protein-2. Spine J 11:1027-1032, 2011

13. Hofstetter CP, Shin B, Tsiouris AJ, Elowitz E, Härtl R: Radiographic and clinical outcome after 1- and 2-level transsacral axial interbody fusion. Clinical article. J Neurosurg Spine 19:454-463, 2013

14. Hsieh PC, Koski TR, O’Shaughnessy BA, Sugrue P, Salehi S, Ondra S, et al: Anterior lumbar interbody fusion in comparison with transforaminal lumbar interbody fusion: implications for the restoration of foraminal height, local disc angle, lumbar lordosis, and sagittal balance. J Neurosurg Spine 7:379-386, 2007

15. Issack PS, Boachie-Adjei O: Axial lumbosacral interbody fusion appears safe as a method to obtain lumbosacral arthrodesis distal to long fusion constructs. HSS J 8:116-121, 2012

16. Kuklo TR: Principles for selecting fusion levels in adult spinal deformity with particular attention to lumbar curves and double major curves. Spine (Phila Pa 1976) 31 (19 Suppl):S132S138, 2006

17. Ledet EH, Tymeson MP, Salerno S, Carl AL, Cragg A: Biomechanical evaluation of a novel lumbosacral axial fixation device. J Biomech Eng 127:929-933, 2005

18. Li XM, Zhang YS, Hou ZD, Wu T, Ding ZH: The relevant anatomy of the approach for axial lumbar interbody fusion. Spine (Phila Pa 1976) 37:266-271, 2012

19. Lindley EM, McCullough MA, Burger EL, Brown CW, Patel VV: Complications of axial lumbar interbody fusion. Clinical article. J Neurosurg Spine 15:273-279, 2011

20. MacMillan M, Fessler RG, Gillespy M, Montgomery WJ: Percutaneous lumbosacral fixation and fusion: anatomic study and two-year experience with a new method. Neurosurg Clin N Am 7:99-106, 1996

21. Marchi L, Oliveira L, Coutinho E, Pimenta L: Results and complications after 2-level axial lumbar interbody fusion with a minimum 2-year follow-up. Clinical article. J Neurosurg Spine 17:187-192, 2012

22. Marotta N, Cosar M, Pimenta L, Khoo LT: A novel minimally invasive presacral approach and instrumentation technique for 


\section{AxiaLIF for lumbosacral interbody fusion}

anterior L5-S1 intervertebral discectomy and fusion. Technical note and case presentations. Neurosurg Focus 20(1):E9, 2006

23. Mazur MD, Duhon BS, Schmidt MH, Dailey AT: Rectal perforation after AxiaLIF instrumentation: case report and review of the literature. Spine J 13:e29-e34, 2013

24. Mok JM, Hu SS: Surgical strategies and choosing levels for spinal deformity: how high, how low, front and back. Neurosurg Clin N Am 18:329-337, 2007

25. Moskowitz A: Transforaminal lumbar interbody fusion. Orthop Clin North Am 33:359-366, 2002

26. Sasso RC, Kenneth Burkus J, LeHuec JC: Retrograde ejaculation after anterior lumbar interbody fusion: transperitoneal versus retroperitoneal exposure. Spine (Phila Pa 1976) 28: 1023-1026, 2003

27. Sharma AK, Kepler CK, Girardi FP, Cammisa FP, Huang RC, Sama AA: Lateral lumbar interbody fusion: clinical and radiographic outcomes at 1 year: a preliminary report. J Spinal Disord Tech 24:242-250, 2011

28. Shen FH, Samartzis D, Khanna AJ, Anderson DG: Minimally invasive techniques for lumbar interbody fusions. Orthop Clin North Am 38:373-386, 2007

29. Siegel G, Patel N, Ramakrishnan R: Rectocutaneous fistula and nonunion after TranS1 axial lumbar interbody fusion L5-S1 fixation. Case report. J Neurosurg Spine 19:197-200, 2013

30. Tobler WD, Ferrara LA: The presacral retroperitoneal approach for axial lumbar interbody fusion: a prospective study of clinical outcomes, complications and fusion rates at a follow-up of two years in 26 patients. J Bone Joint Surg Br 93: 955-960, 2011

31. Tobler WD, Gerszten PC, Bradley WD, Raley TJ, Nasca RJ, Block JE: Minimally invasive axial presacral L5-S1 interbody fusion: two-year clinical and radiographic outcomes. Spine (Phila Pa 1976) 36:E1296-E1301, 2011

32. Vamvanij V, Ferrara LA, Hai Y, Zhao J, Kolata R, Yuan HA: Quantitative changes in spinal canal dimensions using interbody distraction for spondylolisthesis. Spine (Phila Pa 1976) 26:E13-E18, 2001

33. Vibert BT, Sliva CD, Herkowitz HN: Treatment of instability and spondylolisthesis: surgical versus nonsurgical treatment. Clin Orthop Relat Res 443:222-227, 2006

34. Weistroffer JK, Perra JH, Lonstein JE, Schwender JD, Garvey TA, Transfeldt EE, et al: Complications in long fusions to the sacrum for adult scoliosis: minimum five-year analysis of fifty patients. Spine (Phila Pa 1976) 33:1478-1483, 2008

Manuscript submitted October 12, 2013.

Accepted February 21, 2014.

Please include this information when citing this paper: DOI: 10.3171/2014.2.FOCUS13467.

Address correspondence to: Paul S. Issack, M.D., Ph.D., Hospital for Special Surgery, 535 E. 70th St., New York, NY 10021. email: PSIssack@aol.com. 